\title{
Recent developments in neurosurgical spinal cord monitoring
}

\author{
J Schramm MD, M Kurthen MD
}

Department of Neurosurgery, University Hospital, Sigmund-Freud-Strasse 25, D-5300
Bonn 1, Germany.

In a review 8 years ago, the then current status of intraoperative spinal cord monitoring (SCM) was discussed. ${ }^{1}$ Concerning future developments, that article concluded that the major challenge lay in (a) the improvement of the reliability and clinical relevance of somatosensory evoked potential (SEP) monitoring, where the incidence of false-negative and false-positive results had to be reduced, and (b) the application of new techniques like motor evoked potential (MEP) monitoring, which might turn out to be a method complementary to the SEP approach.

Since that time, there has been a considerable amount of newly published results from intraoperative SCM, although clinical articles on exclusively neurosurgical SCM are rare (Table I). A selective literature search for the present review (primarily for the time from 1988 to 1992) yielded more than 200 citations. Eighty-one studies entered into the final evaluation; among these were 3 conference proceedings, ${ }^{15-17} 6$ book chapters, ${ }^{7,11,18-21}$ and 10 review articles. ${ }^{22-31}$ Further, 40 clinical articles, and 22 articles on experimental work were counted. In particular, experimental studies in animals have given support to clinical monitoring by exploring the usefulness of new stimulation and recording techniques. ${ }^{24}$ This reappraisal only considers recent work on SEP and MEP in neurosurgical SCM with some experimental studies relevant to clinical SCM. Spinal cord monitoring in orthopaedic surgery is not evaluated in this review for reasons detailed in the article.

Key words: spinal cord monitoring; somatosensory evoked potentials; motor evoked potentials.

\section{SEP monitoring}

\section{Different techniques}

Neurosurgical SEP monitoring has increasingly been carried out with spinal rather than scalp recording, although in accordance with previous studies, ${ }^{19}$ noninvasive SEP recording from the scalp ${ }^{10.12 .32}$ and from Erb's point and neck ${ }^{33}$ in various neurosurgical procedures was also found to be useful. A new approach can be seen in the use of dermatomal SEP, latencies of which appeared to be reliable indicators of adequate lumbar nerve root decompression intraoperatively. ${ }^{34}$ Cervical dermatomal SEP and SCEP after finger stimulation ${ }^{35}$ may become a helpful device for intraoperative electrodiagnosis or monitoring of decompression procedures in cervical spinal surgery. As for spinal recordings, two methods are to be distinguished. Conductive spinal cord evoked potentials (SCEP) can be obtained from levels clearly above the lesion site after peripheral or spinal ('spinally evoked conductive SCEP') stimulation. ${ }^{36}$ The latter approach is discussed below in the context of other spino-spinal techniques. Segmental SCEP are recorded near the lumbosacral or cervical enlargement after lower or upper extremity nerve stimulation. ${ }^{36} \mathrm{~A}$ disadvantage of this method is the variability of responses dependent on even slight changes of the recording electrode position. ${ }^{37}$ Romstöck $^{9}$ found that while SCEP in thoracolumbar spinal cord surgery were variable and often (48\%) gave false-positive results, cervical recordings were more stable $(0 \%$ falsepositives). Since spinal recordings are less susceptible to anaesthesia effects and require less runs per average than cortical 
Table I Recent clinical studies on spinal cord monitoring in neurosurgical operations

\begin{tabular}{|c|c|c|c|c|c|}
\hline 1st author & $\begin{array}{l}\text { Year of } \\
\text { publication }\end{array}$ & $\begin{array}{l}\text { No of } \\
\text { patients }\end{array}$ & Diagnoses & $\begin{array}{c}\mathrm{SCM} \\
\text { modality }\end{array}$ & $\begin{array}{l}\text { Recording } \\
\text { sites }\end{array}$ \\
\hline $\mathrm{Baba}^{2}$ & 1988 & 36 & $\begin{array}{l}\text { Various spinal cord } \\
\text { diseases }\end{array}$ & SCEP & Epidurally \\
\hline Fukui $^{3}$ & 1991 & 19 & Spinal cord tumours & SCEP & $\begin{array}{l}\text { Spinal cord, peripheral } \\
\text { nerve }\end{array}$ \\
\hline Inghilleri $^{4}$ & 1989 & 10 & $\begin{array}{l}\text { Thoracic spinal cord } \\
\text { tumours; pain } \\
\text { syndromes }\end{array}$ & MEP & Epidurally $\mathrm{C} 7-\mathrm{Th} 5$ \\
\hline Jellinek $^{5}$ & 1991 & 34 & $\mathrm{NpP}$; spinal cord tumours & MEP & Muscle \\
\hline Levy $^{6}$ & 1987 & 45 & Cervical discopathy etc & MEP & $\begin{array}{l}\text { Spinal cord, nerve, } \\
\text { muscle }\end{array}$ \\
\hline Matsuda $^{7}$ & 1989 & 226 & $\begin{array}{l}\text { Mixed orthopaedic and } \\
\text { neurosurgical (tumours } \\
\text { etc) }\end{array}$ & $\begin{array}{l}\text { SCEP, } \\
\text { MEP }\end{array}$ & Epidurally, nerve \\
\hline McDonnell $^{8}$ & 1988 & 4 & Cervical myelopathy & SEP & Scalp \\
\hline Romstöck $^{9}$ & 1988 & 28 & $\begin{array}{l}\text { Various cervical and } \\
\text { thoracic lesions }\end{array}$ & SEP & Epidurally \\
\hline Schramm ${ }^{10}$ & 1986 & 25 & Spinal cord tumours & SEP & $\begin{array}{l}\text { Lumbar, cervical, and } \\
\text { cortical levels }\end{array}$ \\
\hline Tamaki $^{11}$ & 1989 & 500 & $\begin{array}{l}\text { Mixed orthopaedic and } \\
\text { neurosurgical (tumours } \\
\text { etc) }\end{array}$ & SCEP & $\begin{array}{l}\text { Spinal cord (various } \\
\text { levels) }\end{array}$ \\
\hline Watanabe 12 & 1988 & 63 & $\begin{array}{l}\text { Various spinal cord } \\
\text { diseases }\end{array}$ & SEP & Epidurally; scalp \\
\hline Yokogushi $^{13}$ & 1991 & 14 & Spinal cord tumours & SCEP & Spinal cord above lesion \\
\hline Zentner $^{14}$ & 1989 & 50 & $\begin{array}{l}\text { Various spinal cord } \\
\text { diseases }\end{array}$ & MEP & Muscle \\
\hline
\end{tabular}

SEP, this approach is worth pursuing. Finally, it was found that SEP monitoring in dorsal root entry zone (DREZ) lesion procedures for pain relief could predict permanent postoperative neurological deficits ${ }^{38}$ and indicate the extent of histologically defined lesions after DREZ thermal radiofrequency treatment. ${ }^{39}$

\section{Determination of significant changes}

Since SCM can only be accepted if it is of benefit to a considerable proportion of patients monitored, the criteria of significant intraoperative SEP changes must be stated as the basis of a rationale for the adjustment of operative strategy to monitoring data. ${ }^{26,40}$ Due to the variability of intraoperative recordings, ${ }^{9,41,42}$ the criteria of clinically significant changes have mostly been determined retrospectively and arbitrarily. ${ }^{40}$ Amplitude and latency changes are still the parameters most commonly considered in the determination of alarm and intervention criteria. ${ }^{29}$ The further consideration of parameters like wave configuration $^{26}$ or conduction of repetitive stimuli $^{43}$ has not become routine practice. Dependent on the clinical characteristics of the patients monitored and on the stimulation and recording techniques, amplitude decrements between $20 \%{ }^{42}$ and $60 \%{ }^{26}$ and latency increases between $4 \%{ }^{44}$ and $10 \%{ }^{9}$ were found to be associated with the occurrence of postoperative neurological deficits. In patients with neurological disorders, intraoperative responses are particularly variable. ${ }^{9,41,42}$ Since there is still a lack of generally accepted monitoring standards, every clinic must identify and use its own intervention criteria in a series of operations. ${ }^{19,29}$ Evidence for the benefits of SCM is often more conclusive in reports of single cases rather than in the evaluation of larger 
patient groups. Daube, ${ }^{45}$ for example, presented a patient in which reversal of damage occurred during fusion of a traumatic cervical spine fracture, where SEP changes indicated spinal impairment due to excessively tight wires intraoperatively. However, the efficiency of such modifications of surgical strategy cannot be proven unless there are control groups without monitoring or even, paradoxically enough, with monitoring that is ignored by the surgeon. Finally, the problem of false-negative and falsepositive records has not yet been resolved. Whilst false-negatives are rare but of great consequence, false-positives can occur in up to $20 \%$ of monitoring procedures. ${ }^{29}$ With improvement of technology and standardisation of warning and intervention criteria. the proportion of false-positives and falsenegatives can be expected to diminish.

\section{MEP monitoring}

\section{Methodological aspects}

The need for motor tract monitoring is obvious, since SEP are not sensitive to deterioration of anterior spinal pathways. $^{46.47}$ MEP studies in animals have suggested that responses to motor tract stimulations are well correlated to experimentally induced spinal cord lesions. ${ }^{48-51}$ Stimulation can be electrical or magnetic, transcranial, cortical, or spinal; ${ }^{31}$ responses are obtained from muscles, peripheral nerves, or the spine (spino-spinal techniques are discussed below). MEP monitoring is much more easily compromised by the negative effects of general anaesthesia and relaxants than are SEP, but responses under nitrous oxide ${ }^{52-54}$ or propofol $^{5.56}$ anaesthesia have been described as sufficient for a regular monitoring procedure. Furthermore, muscle responses can be efficiently facilitated by additional peripheral nerve stimulation, however, the necessary quantification of its degree proves to be difficult. ${ }^{57.58}$ Generally, electrical stimulation is preferred for its direct impact on the corticospinal tract (D-wave), although high intensity magnetic stimulation may also activate the pyramidal axons directly. ${ }^{59,60}$ Further, spinal responses seem to be less susceptible to the effects of anaesthesia than are peripheral ones, ${ }^{61}$ and prove to be less susceptible to spinal cord alteration than are peripheral nerve and muscle recordings. ${ }^{6}$

\section{Clinical studies}

As for the few clinical reports, Jellinek et $a l^{5}$ successfully monitored 7 out of 8 patients with spinal tumours or arteriovenous malformations and abnormal preoperative motor conduction. They found that permanent loss of MEP (recorded from the dorsal interosseus muscles after transcranial electrical stimulation) was associated with postoperative neurological impairment (one patient), while reversible amplitude and latency changes did not indicate deterioration in neurological function. Similar results were obtained by Kitagawa et al, ${ }^{62}$ who recorded epidurally (Th4-Th12) after transcranial stimulation in cervical spine orthopaedic surgery $(n=20$; one patient with quadriplegia after total loss of MEP). Zentner ${ }^{14}$ presented a larger series of 50 patients with various spinal cord diseases, 43 of whom were monitored successfully. Responses were obtained from thenar and anterior tibial muscles after transcranial electrical stimulation, and amplitude decrement up to $50 \%$ was considered acceptable. On the basis of these conventions, there were no false-negative results, and postoperative neurological status was correctly predicted in $81.4 \%$ of the anterior tibial muscle recordings and $76.2 \%$ of thenar recordings (see Zentner ${ }^{63}$ for further results from cauda equina and spinal cord recording). The disadvantage of this technique is the unwelcome occurrence of muscle contractions as a result of high intensity electrical stimulation. Furthermore, it must be appreciated that the special anaesthesia required for regular recording does not lead to undesirable recall phenomena postoperatively. Levy ${ }^{6}$ applied multilevel recordings from the ligamentum flavum, peripheral nerves and muscles after transcranial or direct stimulation in 98 cases, 45 of them with spinal cord affections. In these patients, MEP recordings did not miss any postoperative neurological deficits, and in a few cases intraoperative MEP deterioration 
led to a modification of operative strategy with subsequent recovery of responses.

\section{Conclusion}

Intraoperative MEP recording after electrical stimulation requires very special anaesthetic techniques which still have to be developed for transcranial magnetic stimulation. Stimulation methods avoiding strong muscle contractions need improvement. These studies indicate that motor tract monitoring can further be developed and may even work in some patients with impaired baseline recordings, which are frequent in neurosurgery. However, there are very few reports with few patients and even less actual influence of monitoring results on surgical strategy. The mere 'prediction' (often stated retrospectively?) of neurological outcome is academic if the monitoring procedure does not help to avoid complications.

\section{Combined SEP and MEP monitoring}

\section{Animal studies}

There are several reports on experimental animal studies with combined SEP and MEP monitoring that are also relevant to SCM in clinical practice. In rats with clip compression injury at $\mathrm{C} 8$, it was found that MEP are generally more sensitive to injury, whereas SEP more precisely distinguish between different degrees of injury; ${ }^{64}$ in this study, transcranially evoked MEP were recorded from the spinal cord and the sciatic nerve. Similarly, in a spinal cord weight drop model in cats, MEP - especially the spinal signal - was more easily affected (impact of $100-150 \mathrm{~g} / \mathrm{cm}$ ) than SEP (200$250 \mathrm{~g} / \mathrm{cm}){ }^{65}$ On the other hand, muscle MEP after single stimuli in rats are less sensitive to light spinal cord injury than SEP. ${ }^{66}$ In a cordorhizotomy model in hogs with cortical or spinal motor stimulation and sciatic nerve recording, MEP failed to indicate sensory tract lesioning, while SEP remained unchanged with severe motor deficits. ${ }^{67}$ These experimental studies suggest that MEP and SEP indeed reflect the functional status of the respective spinal pathways and can be used as complementary techniques in clinical SCM.

\section{Clinical studies}

Matsuda ${ }^{7}$ compared transcranially evoked spinal MEP to cauda-equina-evoked spinal SEP in patients with various spinal cord affections. The course of SCM in 5 operations for intramedullary tumours suggested that SEP and MEP efficiently monitor the respective pathways and that especially the absence of marked changes in MEP - also when combined with major SEP reduction warrants regular continuation of the operation. In a purely orthopaedic study, ${ }^{68} 40$ patients received combined MEP and SEP (conductive ESCP) monitoring during scoliosis surgery. Although there were neither persistent EP changes nor new neurological deficits, the results were illuminating with respect to the general practicability of combined monitoring: in $7(18 \%)$ of the patients, most of them with preoperative motor deficits, SEP but not MEP could be elicited; in $2(5 \%)$, only MEP were recordable, and 2 patients showed no potentials at all. Due to further technical problems, combined monitoring was successful in a total of $28(70 \%)$ patients.

\section{Conclusion}

These results once again indicated that successful SCM is difficult to obtain especially in patients with abnormal baseline recordings, as also stressed previously. $1,23,42$ On the one hand, the combination of two monitoring techniques will increase the proportion of failures; on the other hand, monitoring of one modality may be helpful in the case of failure of the other technique. All in all, the combined SEP/MEP SCM looks promising, although far more genuinely clinical studies are required to justify this optimism.

\section{Spino-spinal recordings}

Spinal cord potentials can be evoked by ascending ${ }^{11,69}$ as well as decending ${ }^{70,71}$ volleys after spinal - mostly epidural - stimulation. These techniques have primarily 
been used for preoperative diagnosis. Clinical $^{11}$ and experimental ${ }^{72}$ studies indicate that responses to spinal stimulation involve both motor and somatosensory tracts in the spinal cord. For example, electrical spinal stimulation at $\mathrm{T} 7$ in the cat results in activity in the L7 ventral and dorsal root, and epidural recording from L3 yields a threecomponent response with the first two peaks reflecting activity in the ventral pathways and the third one representing dorsal column activation. ${ }^{72}$ These data may raise some optimism concerning a combined ascending/descending SCM with rostral and caudal electrodes that can both be used for stimulation and recording. ${ }^{11}$ Turning to clinical studies, Yokogushi ${ }^{13}$ intraoperatively recorded ascending conductive ESCP in 14 cases of spinal cord tumors. While there were neither false-positive results nor any additional postoperative neurological deficits, recordings were found to be of some value since responses improved after decompression in 6 out of 8 patients with abnormal ESCP, thus anticipating postoperative improvement. A similar technique was applied in 36 patients with various cervical spine diseases. ${ }^{2}$ In 7 patients $(19 \%)$, SCM was not successful; only 2 showed more than $50 \%$ amplitude attenuation, but did not develop major new neurological deficits. Altogether, the clinical application of spino-spinal recording in neurosurgical SCM is still in its beginnings. The ideal of a combined ascending/descending SCM could not yet be achieved with that technique. Criteria of significant change (mostly amplitude reduction of more than $50 \%)^{2,13}$ are somewhat arbitrarily defined. If the procedure works, however, it is elegant and may even do away with timeconsuming averaging of signals.

\section{General conclusions and outlook}

Although the work reviewed is instructive and revealing in several respects, it will not suffice to establish SCM as a routine monitoring procedure on neurosurgery of the spinal cord. While considerable progress has been made concerning some special applications and recordings and stimulation tech- niques, the concept of SCM in neurosurgery has still not stood the test of time. This is also due to the fact that there was no successful coordinated effort toward standardisation and unification of SCM procedures, but mainly because many neurosurgical patients have poor, unmonitorable potentials to start with. Up to now, clinical studies have been very heterogenous regarding recording and stimulation sites and techniques and patient selection. Furthermore, there is the problem of the dissociation of relevance and validity of SCM data: in domains like scoliosis surgery, valid results can be obtained in large patient groups without monitoring events and without postoperative neurological deficits; however, in other genuinely neurosurgical domains such as intramedullary tumour surgery, there are smaller series with fluctuating SCM data, sometimes severe pre- and postoperative deficits and deteriorated baseline recordings. But the comparably valid data obtained in the former group are of rather little clinical relevance, while the insecure findings in the latter group might play a genuine role in intraoperative decision making if only they were more reliable and valid. At present, SCM is often completely unsuccessful in problem patients where intraoperative electrophysiological data are desired. Due to these problems in patients with impaired baseline recordings, the application of SCM in neurosurgery in the main is limited. But further progress can be expected if stimulation and recording become more standardised and warning and intervention criteria are stated prospectively; mere 'prediction of outcome' is secondary compared to avoidance of risky surgical manoeuvers. More multilevel recording in both SEP and MEP SCM is desirable in order to determine the optimal recording site. Transcranial and peripheral nerve stimulation techniques are more widely applicable and less invasive than spinal techniques and therefore offer themselves as primary methods with the most realistic prospect of standardisation. Motor tract monitoring is still constrained by various specifically intraoperative recording difficulties which considerably limit the application of this technique. The above critical 
remarks should not be viewed as defeatist. since we explicitly appreciate some promising approaches, one of which might well result in a major breakthrough within the next few years. After all, SCM is something like 'the only game in town', that is, the only method of continuous intraoperative assessment of spinal functions currently available.

\section{References}

1 Schramm J (1985) Spinal cord monitoring. Current status and new developments. Cent Nerv Svstem Trauma 2: 207-225.

2 Baba H, Tomita K, Umeda S, Kawahara N, Nagata S, Nomura et al (1988) Clinical study of spinal cord evoked potentials. In: Ducker TL, Brown RH, editors. Neurophysiology and Standards of Spinal Cord Monitoring. Springer: New York, Berlin, Heidelberg: 216-221.

3 Fukui Y, Satomi K, Okuma T, Kenmotsu K. Kamata M. Ikai T. Hirabayashi K (1991) Intraoperative spinal cord monitoring using evoked spinal cord potentials on spinal cord tumors. In: Shimoji $\mathrm{K}$ et al. editors. Spinal Cord Monitoring and Electrodiagnosis. Springer: New York, Berlin. Heidelberg: 296-304.

4 Inghilleri M, Berardelli A, Cruccu G, Priori A. Manfredi M (1989) Cortico-spinal potentials after transcranial stimulation in humans. J Neurol Neurosurg Psvchiat 52: 970-974.

5 Jellinek D, Jewkes D, Symon L (1991) Noninvasive intraoperative monitoring of motor evoked potentials under propofol anesthesia: effects of spinal surgery on the amplitude and latency of motor evoked potentials. Neurosurgery 29: 551-557.

6 Levy WJ (1987) Clinical experience with motor and cerebellar evoked potential monitoring. Neurosurgery 20: $169-182$.

7 Matsuda H, Shimazu A (1989) Intraoperative spinal cord monitoring using electric responses to stimulation of caudal spinal cord or motor cortex. In: Desmedt JE. editor. Neuromonitoring in Surgery. Elsevier: Amsterdam, New York, Oxford: 175-190.

8 McDonnell DE, Flanigin HF, Sullivan HG (1988) Somatosensory evoked potentials (SEP) intraoperative monitoring during cranial vertebral compression and instability. In: Ducker TL, Brown RH, editors. Neurophysiology and Standards of Spinal Cord Monitoring. Springer: New York, Berlin. Heidelberg: 251-260.

9 Romstöck J, Watanabe E, Schramm J (1988) Variability of epidural SEP from below and above spinal cord lesions - the effect of the lesion on spinal SEP. In: Ducker TL, Brown RH, editors. Neurophysiology and Standards of Spinal Cord Monitoring. Springer: New York, Berlin. Heidelberg: 261-267.

10 Schramm J, Romstöck J, Watanabe E (1986) Intraoperatives Rückenmarkmonitoring. Eigene Ergebnisse und Bestandsaufnahme. Z Orthop 124: 726-731.

11 Tamaki T (1989) Spinal cord monitoring with spinal potentials evoked by direct stimulation of the spinal cord. In: Desmedt JE, editor. Neuromonitoring in Surgery. Elsevier: Amsterdam. New York, Oxford: $139-149$

12 Watanabe E, Schramm J, Romstöck J (1988) Cortical and spinal intraoperative recordings in uneventful monitoring and in cases with neurological changes. In: Ducker TL. Brown RH, editors. Neurophysiologv' and Standards of Spinal Cord Monitoring. Springer: New York. Berlin. Heidelberg: 226-233.

13 Yokogushi K, Katahira G. Yokozawa H, Kawamura H, Yamashita T, Ogiwara N (1991) Analysis of conductive spinal cord function using spinal cord evoked potentials during surgery of spinal cord tumors. In: Shimoji K et al, editors. Spinal Cord Monitoring and Electrodiagnosis. Springer: New York. Berlin. Heidelberg: 396-402.

14 Zentner J (1989) Noninvasive motor evoked potential monitoring during neurosurgical operations on the spinal cord. Neurosurgery 24: 709-712.

15 Ducker TL, Brown RH, editors (1988) Neurophysiology and Standards of Spinal Cord Monitoring. Springer: New York, Berlin, Heidelberg.

16 Schramm J, Møller AR, editors. (1991) Intraoperative neurophysiological monitoring in neurosurgery. Springer: New York, Berlin, Heidelberg.

17 Shimoji K et al, editors (1991) Spinal Cord Monitoring and Electrodiagnosis. Springer: New York, Berlin. Heidelberg.

18 Levy WJ (1988) The electrophysiological monitoring of motor pathways. In: Clinical Neurosurgery (Proceedings of the Congress of Neurological Surgeons, New Orleans, 1986). Williams \& Wilkins. Baltimore: 239-260.

19 Nuwer MR (1986) Spinal cord monitoring. In: Nuwer MR. Evoked Potential Monitoring in the Operation Room. New York: Raven Press, 1986.

20 Nuwer MR (1989) Monitoring spinal cord surgery with cortical somatosensory evoked potentials. In: Desmedt JE, editor. Neuromonitoring in Surgery. Elsevier: Amsterdam, New York, Oxford: 151-164.

21 Young W, Mollin D (1989) Intraoperative somatosensory evoked potentials monitoring of spinal surgery. In: Desmedt JE, editor. Neuromonitoring in Surgery. Elsevier: Amsterdam, New York. Oxford: 165-173.

22 Ben-David B (1988) Spinal cord monitoring. Orthop Clin North Am 19: 427-448.

23 Daube JR (1991) Monitoring of spine surgery with evoked potentials. In: Schramm J, Møller AR, editors. 
Intraoperative Neurophysiological Monitoring in Neurosurgery. Springer: New York, Berlin, Heidelberg: 127-137.

24 Fernandez E, Pallini R, Marchese E, Talmonti G (1991) Experimental studies on spinal cord injuries in the last fifteen years. Neurol Res 13: 138-159.

25 Frazier WT (1988) Effects of anesthetic drugs on spinal cord monitoring: an update. In: Ducker TL, Brown RH, editors. Neurophysiology and Standards in Spinal Cord Monitoring. Springer: New York, Berlin, Heidelberg: $125-139$

26 Jones SJ, Howard L, Shawkat F (1988) Criteria for detection and pathological significance of response decrement during spinal cord monitoring. In: Ducker TL, Brown RH, editors. Neurophysiology and Standards in Spinal Cord Monitoring. Springer: New York, Berlin, Heidelberg: 201-206.

27 Loughnan BA. Hall GM (1989) Spinal cord monitoring 1989. Br J Anaesth 63: 587-594.

28 Mostegl A, Bauer R (1989) Intraoperative Überwachung von Wirbelsäuleneingriffen mit evozierten Potentialen. Orthopäde 18: 155-161.

29 Nash CL. Brown RH (1989) Current concepts review. Spinal cord monitoring. J Bone Joint Surg 71: 627-630.

30 Ronner SF (1990) Neurosurgical applications for intraoperative stimulation. Int Anesth Clin 28: 174-179.

31 Rothwell JC. Day BL, Thompson PD. Boyd SG, Marsden CD (1989) Motor cortical stimulations in intact man: Physiological mechanisms and application in intraoperative monitoring. In: Desmedt JE, editor. Neuromonitoring in Surgery. Elsevier: Amsterdam, New York, Oxford: 71-98.

32 Bieber E. Tolo V. Uematsu S (1988) Spinal cord monitoring during posterior spinal instrumentation and fusion. Clin Orthop 229: 121-124.

33 Urasaki E. Wada S, Matsukado Y, Yokota A. Matsuoka S (1988) Monitoring of short-latency somatosensory evoked potentials during surgery for cervical cord and posterior fossa lesions. Neurol Med Chir (Tokyo) 28: 546-552.

34 Herron LD, Trippi AC. Gonyeau M (1987) Intraoperative use of dermatomal somatosensory evoked potentials in lumbar stenosis surgery. Spine 12: 379-383.

35 Takahashi H, Suzuki I, Ishiyima B (1991) Somatotopical evoked responses from the spinal cord and cerebral cortex to finger stimulation. In: Shimoji K et al, editors. Spinal Cord Monitoring and Electrodiagnosis. Springer: New York. Berlin. Heidelberg: 177-185.

36 Ertekin C (1988) Intradural spinal recordings (particular reference to invasive methods). In: Ducker TL, Brown HR, editors. Neurophysiology and Standards of Spinal Cord Monitoring. Springer: New York, Berlin, Heidelberg: 82-99.

37 Goya T. Miyahara S, Mikura T. Kinoshita K (1991) Intraoperative monitoring of segmental evoked spinal cord potentials in cervical lesions. In: Shimoji K et al. editors. Spinal Cord Monitoring and Electrodiagnosis. Springer: New York. Berlin, Heidelberg: $370-380$.

38 Lunsford LD, Bennett MH (1989) Evoked-potential monitoring during dorsal root entry zone surgery. Stereotact Funct Neurosurg 53: 233-246.

39 Bennett MH. Lunsford LD. Akin O. Martinez AJ (1989) Evoked potential monitoring during dorsal root entry zone surgery. An experimental animal model. Stereotact Funct Neurosurg 53: 247-260.

40 Schramm J (1988) Acute evoked potential changes in operative treatment: a summary. In: Ducker TL, Brown HR, editors. Neurophysiology and Standards of Spinal Cord Monitoring. Springer: New York, Berlin. Heidelberg: 268-273.

41 Lubicky JL. Spadaro JA. Yaun HA, Fredrickson BE. Henderson N (1989) Variability of somatosensory cortical evoked potential monitoring during spinal surgery. Spine 14: 790-798.

42 Veilleux M, Daube JR, Cucchiara RF (1987) Monitoring of cortical evoked potentials during surgical procedures on the cervical spine. Mayo Clin Proc 62: 256-264.

43 Sakatani K. Ohta T, Yamagata Y. Shimo-Oku M (1988) Effects of spinal cord compression on repetitive impulse conduction of ascending fibers in the dorsal column. In: Ducker TL. Brown HR, editors. Neurophysiology and Standards of Spinal Cord Monitoring. Springer; New York, Berlin, Heidelberg: $53-57$.

44 Salzman SK. Dabney KW. Mendez AA, Beauchamp JT, Daley JC, Freeman GM et al (1988) The somatosensory evoked potential predicts neurologic deficits and serotonergic pathochemistry after spinal distraction injury in experimental scoliosis. J Neurotrauma 5: 173-186.

45 Daube JR (1989) Intraoperative monitoring by evoked potentials for spinal cord surgery: the pros. Electroenceph Clin Neurophysiol 73: 374-377.

46 Zornow MH, Drummond JC (1989) Intraoperative somatosensory evoked responses recorded during onset of the anterior spinal artery syndrome. J Clin Monit 5: 243-246.

47 Rosenberg JN (1991) Somatosensory and magnetic evoked potentials in a postoperative paraparetic patient: case report. Arch Phys Med Rehabil 72: 154-156.

48 Fehlings MG, Tator CH, Linden RD. Piper IR (1987) Motor evoked potentials recorded from normal and spinal cord-injured rats. Neurosurgery 20: $125-130$.

49 Owen JH. Naito M, Bridwell KH. Oakley DM (1990) Relationship between duration of spinal cord ischemia and postoperative neurologic deficits in animals. Spine 15: 846-851.

50 Shiau JS, Zappulla RA. Nieves J (1992) The effect of graded spinal cord injury on the extrapyramidal and pyramidal motor evoked potentials of the rat. Neurosurgery 30: 76-84. 
51 Zileli M, Taniguchi M, Cedzich C, Schramm J (1989) Vestibulospinal evoked potential versus motor evoked potential monitoring in experimental spinal cord injuries of cats. Acta Neurochir (Wien) 101: 141-148.

52 Edmonds HL, Paloheimo MPJ, Backman MH, Johnson JR, Holt RT, Shields CB (1989) Transcranial magnetic motor evoked potentials (tcMMEP) for functional monitoring of motor pathways during scoliosis surgery. Spine 14: 683-686.

53 Zentner J, Ebner A (1989) Nitrous oxide suppresses the electromyographic response evoked by electrical stimulation of the motor cortex. Neurosurgery 24: 60-62.

54 Schmid UD, Boll J, Liechti S, Schmid J, Hess CW (1992) Influence of some anesthetic agents on muscle responses to transcranial magnetic cortex stimulation: a pilot study in humans. Neurosurgery 30: 85-92.

55 Jellinek D, Platt M, Jewkes D, Symon L (1991) Effects of nitrous oxide on motor evoked potentials recorded from sceletal muscle in patients under total anesthesia with intravenously administered propofol. Neurosurgery 29: 558-562.

56 Keller BP, Haghighi SS, Oro JJ, Eggers GWN (1992) The effects of propofol anesthesia on transcortical electric evoked potentials in the rat. Neurosurgery 30: 557-560.

57 Taniguchi M, Schramm J (1991) Motor evoked potentials facilitated by an additional peripheral nerve stimulation. In: Levy WJ et al, editors. Magnetic Motor Stimulation: Basic Principles and Clinical Experience (EEG Suppl. 43). Elsevier: Amsterdam, New York, Oxford: 202-211.

58 Taniguchi M, Schramm J, Cedzich C (1991) Recording of myogenic motor evoked potentials (mMEP) under general anesthesia. In: Schramm J, Møller AR, editors. Intraoperative Neurophysiological Monitoring in Neurosurgery. Springer: New York, Berlin, Heidelberg: 72-87.

59 Berardelli A, Inghilleri M, Cruccu G, Manfredi M (1991) Corticospinal potentials after electrical and magnetic stimulation in man. In: Levy WJ et al, editors. Magnetic Motor Stimulation: Basic Principles and Clinical Experience (EEG Suppl. 43). Elsevier: Amsterdam, New York, Oxford: 147-154.

60 Thompson PD, Day BL, Crockard HA, Calder I, Murray MNF, Rothwell JC et al (1991) Intra-operative recording of motor tract potentials at the cervico-medullary junction following scalp electrical and magnetic stimulation of the motor cortex. J Neurol Neurosurg Psychiat 54: 618-623.

61 Katayama Y, Tsubokawa T, Maejima S, Hirayama T, Yamamoto T (1988) Corticospinal direct response in humans: identification of the motor cortex during intracranial surgery anesthesia. J Neurol Neurosurg Psychiat 51: 50-59.

62 Kitagawa H, Itoh T, Takano H, Takakuwa K, Yamamoto N, Yamada H et al (1989) Motor evoked potential monitoring during upper cervical spine surgery. Spine 14: 1078-1083.

63 Zentner J (1991) Motor evoked potential monitoring during neurosurgical operations on the spinal cord. Neurosurg Rev 14: 29-36.

64 Fehlings MG, Tator CH, Linden RD (1989) The relationships among the severity of spinal cord injury, motor and somatosensory evoked potentials and spinal cord blood flow. Electroenceph Clin Neurophysiol 74: $241-259$.

65 Levy WJ, McCaffrey M, York D (1986) Motor evoked potential in cats with acute spinal cord injury. Neurosurgery 19: 9-19.

66 Zileli M, Schramm J (1991) Motor versus somatosensory evoked potential changes after acute experimental spinal cord injury in rats. Acta Neurochir (Wien) 108: 140-147.

67 Owen JH, Jenny AB, Naito M, Weber K, Bridwell KH, McGhee R (1989) Effects of spinal cord lesioning on somatosensory and neurogenic-motor evoked potentials. Spine 14: 673-682.

68 Hicks RG, Burke DJ, Stephen JPH (1991) Monitoring spinal cord function during scoliosis surgery with Cotrel-Dubousset instrumentation. Med J Austral 154: 82-86.

69 Kawahara N, Baba H, Nagata S, Kikuchi Y, Tomita K, Nomura S et al (1991) Experimental studies on the spinal cord evoked potentials in cervical spine distraction injuries. In: Shimoji K et al, editors. Spinal Cord Monitoring and Electrodiagnosis. Springer: New York, Berlin, Heidelberg: 107-115.

70 Shimoji K, Fujioka H, Maruyama Y, Shimizu H, Hokari T, Takada T (1988) Spinal cord potentials (SCPs) produced by descending volleys in man. In: Ducker TL, Brown HR, editors. Neurophysiology and Standards of Spinal Cord Monitoring. Springer: New York, Berlin, Heidelberg: 114-121.

71 Tsuboka T, Katayama Y, Maejima S, Hirayama T, Yamamoto T (1988) Usefulness of motor evoked potentials (pyramidal D-response) for assessment of spinal cord injury. In: Ducker TL, Brown RH, editors. Neurophysiology and Standards of Spinal Cord Monitoring. Springer: New York, Berlin, Heidelberg: 106-113.

72 Niznik G, Transfeldt EE, Shichijo F, Oshima T., Pomeranz B (1990) Spinal sensory and motor tract activation after epidural electrical stimulation in the cat. Spine 15: 623-629. 